\title{
Human Capital Mahasiswa Universitas Terbuka Sebagai Guru Honorer (Studi Kasus: Guru Honorer di SD Negeri 01 Pangkalan, SD Negeri 10 Pangkalan dan MIS Pangkalan, Kecamatan Pangkalan Koto Baru, Kabupaten Lima Puluh Kota)
}

\author{
Fadilatur Rahmi ${ }^{1}$, Junaidi Junaidi' ${ }^{2}$ Reno Fernandes ${ }^{3}$ \\ 1,2,3 Universitas Negeri Padang
}

Email: fadilaturrahmi2@gmail.com, junaidisatir@gmail.com, renofernandes@ fis.unp.ac.id.

\begin{abstract}
Abstrak
Penelitian ini dilatarbelakangi oleh ketertarikan peneliti dalam melihat mahasiswa Universitas Terbuka yang menjadi guru honorer di SD Negeri 01 Pangkalan, SD Negeri 10 Pangkalan dan MIS Pangkalan. Penelitian ini bertujuan untuk mengetahui human capital mahasiswa Universitas Terbuka sebagai guru honorer di SD Negeri 01 Pangkalan, SD Negeri 10 Pangkalan dan MIS Pangkalan, Kecamatan Pangkalan Koto Baru, Kabupaten Lima Puluh Kota. Penelitian ini dianalisis dengan teori yang dikamukakan oleh Theodore W.Schultz. Penelitian ini menggunakan pendekatan kualitatis tipe studi kasus, teknik pemilihan informan purpose sampling dengan jumlah informan 18 orang. Pengumpulan data dilakukan dengan cara wawancara, observasi, dan dokumentasi yang dianalisis dengan menggunakan teknik analisis data dari Miles dan Huberman. Hasil penelitian menunjukkan bahwa Hasil penelitian menunjukkan bahwa human capital mahasiswa Universitas Terbuka sebagai guru honorer terlihat dari enam perilaku yaitu rajin bertanya dengan guru tetap termasuk aspek pengetahuan, memiliki sifat pantang menyerah termasuk aspek produktifitas kerja, memiliki ide dalam mengelola kelas termasuk aspek kreativitas, memiliki pengalaman dalam kegiatan ekstrakurikuler sehingga dekat dengan peserta didik termasuk aspek keterampilan dan memiliki ide dalam kegiatan sekolah termasuk aspek ide /gagasan.
\end{abstract}

Kata Kunci: Human Capital, Guru Honorer.

\begin{abstract}
This research was motivated by the interest of researchers in seeing Open University students who became honorary teachers in Pangkalan 01 Elementary School, SD Negeri 10 Pangkalan and MIS Pangkalan. This study aims to determine the human capital of Open University students as honorary teachers in Pangkalan 01 Elementary School, SD Negeri 10 Pangkalan and MIS Pangkalan, Pangkalan Koto Baru District, Lima Puluh Kota Regency. This research was analyzed by a theory launched by Theodore W.Schultz. This study uses a qualitative type of case study approach, the technique of selecting purpose sampling informants with 18 informants. Data collection is done by means of interviews, observations, and documentation analyzed using data analysis techniques from Miles and Huberman. The results showed that the results showed that the human capital of Open University students as honorary teachers were seen from six behaviors, namely diligent in asking questions with permanent teachers including aspects of knowledge, having an unyielding nature including work productivity aspects, having ideas in managing classes including aspects of creativity, having experience in extracurricular activities so that it is close to students including aspects of skills and having ideas in school activities including aspects of ideas.
\end{abstract}

Keywords: Human Capital, Honorary Teacher 


\section{Pendahuluan}

Pendidikan dalam arti sederhananya sebagai usaha manusia untuk membina kepribadiannya sesuai dengan nilai-nilai di dalam masayarakat dan kebudayaannya ${ }^{1}$. Dalam perkembangannya, istilah pendidikan atau paedagogie berarti bimbingan atau pertolongan yang diberikan dengan sengaja oleh orang dewasa agar ia menjadi dewasa. Selanjutnya, pendidikan juga diartikan sebagai usaha yang dijalankan oleh seseorang atau kelompok orang lain agar menjadi dewasa atau mencapai tingkat hidup atau penghidupan yang lebih tinggi dalam arti mental. ${ }^{2}$

Salah satu terlaksananya proses pendidikan adalah pendidik. Pendidik ialah orang yang memikul pertanggungjawaban untuk mendidik. Dwi Nugroho Hidayanto, menginventarisasi bahwa pengertian pendidik meliputi orang dewasa, orang tua, guru, pemimpin masyarakat dan pemimpin agama. ${ }^{3}$ Sejalan dengan hal itu, Pasal 1 Undang-undang No.20 Tahun 2003 tentang Sistem Pendidikan Nasional mengatakan bahwa, pendidik adalah tenaga kependidikan yang berkualifikasi sebagai guru, dosen, konselor, pamong belajar, widyaiswara, tutor, instruktur, fasilitator, dan sebutan lain sesuai dengan kekhususannya, serta berpartisipasi dalam menyelenggarakan kependidikan ${ }^{4}$. Hal ini menunjukkan bahwa salah satu pendidik adalah guru.

Guru sebagai seorang pendidik memiliki syarat yang harus dipenuhi. Adapun syarat tersebut terdapat dalam Peraturan Pemerintah Republik Indonesia Nomor 19 Tahun 2017 pasal 1 butir 2 ditetapkan bahwa: Guru harus memiliki kualifikasi akademik yaitu ijazah jenjang pendidikan akademik yang harus dimiliki oleh guru sesuai dengan jenis, jenjang, dan satuan pendidikan formal di tempat penugasan ${ }^{5}$. Sejalan dengan itu, dalam undang-undang Republik Indonesia No.14 Tahun 2005 tentang Guru dapat dilihat pada Pasal 8 yaitu guru wajib memiliki kualifikasi akademik, kompetensi, sertifikat pendidik, sehat jasmani dan rohani, serta memiliki kamampuan untuk mewujudkan tujuan pendidikan nasional. Pasal 9 memuat tentang kualifikasi akademik sebagaimana dimaksud dalam Pasal 8 diperoleh melalui pendidikan tinggi program sarjana atau program diploma empat, dan dalam Pasal 10 memuat tentang kompetensi guru sebagaimana dimaksud dalam Pasal 8 meliputi kemampuan pedagogik, kompetensi kepribadian, kompetensi sosial dan kompetensi profesional yang diperoleh melalui pendidikan profesi. $^{6}$

Di Indonesia, fenomena guru yang mengajar tidak memenuhi standar pendidikan cukup banyak terjadi. Berdasarkan catatan Human Development Index (HDI) di Global Competitive Report tahun 2013 diketahui bahwa di Indonesia terdapat 40\% guru SLTP dan SMA 43\% belum layak mengajar di jenjang masing-masing. Selain itu, Toharun mengatakan bahwa 17,2\% guru atau setara dengan 69.477 guru mengajar bukan bidang studinya. Balitbang Kementerian Pendidikan Nasional tahun 2004 menunjukkan bahwa di tingkat SMP terdapat

\footnotetext{
${ }^{1}$ Yuliani, R., Junaidi, J., \& Fernandes, R. (2018). Faktor Pendorong Anak Nelayan Melanjutkan Pendidikan Ke Jenjang SLTA (Studi Kasus: Desa Naras I Kecamatan Pariaman Utara Kota Pariaman). Jurnal Perspektif, 1(4), 44-50.

${ }^{2}$ Hasbullah. Dasar-Dasar Ilmu Pendidikan, Jakarta, Rajawali Pers, 2012, hal 1

${ }^{3}$ Ibid, hal 17

4 Undang-Undang Republik Indonesia Nomor 20 Tahun 2003 Tentang Sistem Pendidikan Nasional. http://www.kelembagaan.risetdikti.go.id, diunduh tanggal 28 Oktober 2018

${ }^{5}$ Peraturan Pemerintah Republik Indonesia Nomor 19 Tahun 2017 Tentang Perubahan Atas Peraturan Pemerintah Nomor 74 Tahun 2008 Tentang Guru. http://www.hukumonline.com, diunduh tanggal 16 Desember 2018

${ }^{6}$ Sindikker.dikti.go.id/dok/uu/uu no 142005 (diunduh pada hari Minggu, tanggal 7 Mei 2017)
} 
$35,9 \%$ dari total guru sebanyak 466.748 orang yang dinilai tidak layak mengajar. ${ }^{7}$ Kekurangan tenaga pendidik untuk beberapa mata pelajaran tertentu menyebabkan guru harus mengajar mata pelajaran yang tidak sesuai dengan bidang yang diampunya. Hal ini menunjukkan kualitas pengajar di Indonesia belum memenuhi standar pelaksanaan pendidikan.

Kondisi serupa juga terjadi di Pangkalan, Kecamatan Pangkalan Koto Baru, Kabupaten Lima Puluh Kota. Berikut adalah Data Referensi Kementerian Pendidikan dan Kebudayaan ${ }^{8}$. Terdapat 9 Sekolah Dasar, 1 Sekolah Menengah Pertama, 1 Sekolah Menengah Atas, dan 1 Sekolah Menengah Kejuruan dengan jumlah siswa yang bervariasi. Sedangkan jumlah guru di Kecamatan Pangkalan Koto Baru berdasarkan Data Pokok Pendidikan Dasar dan Menengah, Direktorat Jenderal Pendidikan Dasar dan Menengah, Kementerian Pendidikan dan Kebudayaan ${ }^{9}$ sebagai berikut:

Tabel 1. Jumlah guru di Kecamatan Pangkalan Koto Baru

\begin{tabular}{ccccccccc}
\hline & SD & \multicolumn{4}{c}{ SMP } & \multicolumn{3}{c}{ SMA } \\
\hline L & P & JML & L & P & JML & L & P & JML \\
\hline 34 & 219 & 253 & 13 & 71 & 84 & 13 & 44 & 57 \\
\hline
\end{tabular}

(Sumber: Data Pokok Pendidikan Dasar dan Menengah, Direktorat Jenderal Pendidikan Dasar dan Menengah, Kementerian Pendidikan dan Kebudayaan tahun 2018)

Berdasarkan data diatas terdapat 253 jumlah guru di Kecamatan Pangkalan Koto Baru yang tercatat. Diantara guru tersebut terdapat guru yang masih berstatus mahasiswa yang menjadi guru honorer di sekolah dasar. Kondisi ini terjadi karena kurangnya guru sekolah dasar yang ada di Pangkalan. Berikut adalah data guru tetap dan guru honorer yang ada di Pangkalan.

Tabel 2. Jumlah Guru Tetap dan Guru Honorer di Pangkalan Koto Baru

\begin{tabular}{|c|c|c|c|c|c|c|}
\hline No & $\begin{array}{c}\text { Nama } \\
\text { Sekolah }\end{array}$ & $\begin{array}{c}\text { Jumlah } \\
\text { Guru }\end{array}$ & Nama Guru Honor & Jurusan & Semester & Mulai Mengajar \\
\hline \multirow[t]{3}{*}{1} & \multirow{3}{*}{$\begin{array}{l}\text { SD Negeri } 01 \\
\text { Pangkalan }\end{array}$} & \multirow[t]{3}{*}{14 orang } & Ardina & PGSD & Semester 5 & Semester 1 \\
\hline & & & Asmarni & PGSD & Semester 5 & Semester 1 \\
\hline & & & Khairun Nisa' & PGSD & Semester 5 & Semester 1 \\
\hline \multirow[t]{5}{*}{2} & \multirow[t]{5}{*}{$\begin{array}{l}\text { SD Negeri } 10 \\
\text { Pangkalan }\end{array}$} & \multirow[t]{5}{*}{13 orang } & Desi Refina & PGSD & Semester 8 & Semester 1 \\
\hline & & & Titi Oktavia & PGSD & Semester 5 & Semester 1 \\
\hline & & & Surga Nur & PGSD & Semester 5 & Semester 1 \\
\hline & & & Dela Fauzana & PGSD & Semester 5 & Semester 1 \\
\hline & & & Muharmi & PGSD & Semester 5 & Semester 1 \\
\hline \multirow[t]{3}{*}{3} & \multirow[t]{3}{*}{$\begin{array}{l}\text { SD MIS } \\
\text { Pangkalan }\end{array}$} & \multirow[t]{3}{*}{14 orang } & Resti Amelia & PGSD & Semester 8 & Semester 1 \\
\hline & & & Desmawati & PGSD & Semester 8 & Semester 1 \\
\hline & & & $\begin{array}{l}\text { Resti Amelia } \\
\text { Muharrahmi }\end{array}$ & $\begin{array}{l}\text { PGSD } \\
\text { PGSD }\end{array}$ & $\begin{array}{l}\text { Semester } 8 \\
\text { Semester } 8\end{array}$ & $\begin{array}{l}\text { Semester } 1 \\
\text { Semester } 1\end{array}$ \\
\hline
\end{tabular}

\footnotetext{
${ }^{7}$ Jurnal Pendidikan: Teori, Penelitian, dan Pengembangan. Volume: 2 Nomor 4 Bulan April Tahun 2017.

Halaman 516-523,http://www.media.neliti.com, diunduh tanggal 28 Oktober 2018

${ }^{8}$ Data Referensi Kementerian Pendidikan dan Kebudayaan. http://www.referensi.data.kemdikbud.go.id, diunduh tanggal 28 Oktober 2018

9 Data Pokok Pendidikan Dasar dan Menengah, Direktorat Jenderal Pendidikan Dasar dan Menengah, Kementerian Pendidikan dan Kebudayaan, diunduh 28 Oktober 2018
}

Jurnal Perspektif Vol. 2, No. 2, Th. 2019 
Dari data yang peneliti dapatkan, semua dari guru di atas adalah yang berstatus mahasiswa. Mereka adalah mahasiswa universitas terbuka yang telah menjadi guru honorer dari awal masuk kuliah. Setelah mereka terdaftar sebagai mahasiswa Universitas Terbuka, barulah mereka mengajar sebagai guru honorer. Pada perguruan tinggi, semestinya proses pembelajaran dilakukan secara berkesinambungan, tetapi tidak demikian dengan proses perkuliahan pada Universitas Terbuka. Perkuliahan dilaksanakan pada hari Sabtu dan Minggu dengan mendatangkan mentor sebagai pengajar. Sebelum perkuliahan berlangsung mahasiswa dibekali modul sebagai pegangan, sehingga pada hari perkuliahan tugas mentor adalah memperjelas materi yang belum dipahami mahasiswa.

Penelitian ini bertujuan untuk mengetahui human capital Mahasiswa Universitas Terbuka Sebagai Guru Honorer di SD Negeri 01 Pangkalan, SD 10 Pangkalan dan MIS Pangkalan Kecamatan Pangkalan Koto Baru, Kabupaten Lima Puluh Kota. Penelitian ini dianalisis oleh Human capital theory yang dikemukakan oleh Theodore W.Schultz yang menganggap manusia sebagai suatu bentuk modal sebagaimana bentuk kapital lainnya, seperti mesin, teknologi, tanah, uang dan material. Manusia yang memiliki modal ketika melakukan peran dengan sungguh-sungguh akan mendapatkan hasil yang luar biasa.

\section{Metodologi Penelitian}

Penelitian ini menggunakan penelitian kualitatif dengan tipe studi kasus. Penelitian kualitatif adalah aktifitas mengkaji, memahami, menemukan, mengenali sebuah fenomena sosial budaya (manusia dan kelompok sosialnya) dengan cara memahami apa yang ada di balik fenomena tersebut. Metode studi kasus yang dalam penelitian ini diharapkan mampu memberikan gambaran yang menyeluruh dan mendalam mengenai human capital mahasiswa Universitas Terbuka dalam mengajar di Pangkalan Koto Baru, Kabupaten Lima Puluh Kota. Dengan data yang didapatkan penulis mampu menjelaskan dan mendeskripsikan permasalahan penelitian mengenai human capital mahasiswa Universitas Terbuka dalam mengajar di Pangkalan Koto Baru, Kabupaten Lima Puluh Kota. Informan dalam penelitian ini adalah: guru honorer, guru tetap, peserta didik dan orang tua peserta didik SD Negeri 01 Pangkalan, SD 10 Pangkalan dan MIS Pangkalan Kecamatan Pangkalan Koto Baru, Kabupaten Lima Puluh Kota. Teknik pengumpulan data yang digunakan adalah purpose sampling atau sampel bertujuan dengan jumlah informan 18 orang. Teknik pengumpulan data yang digunakan yaitu Pengamatan (observasi), wawancara mendalam dan studi dokumentasi. Penelitian ini dianalisis dengan mengunggunakan teknik analisis data dari Miles dan Huberman (reduksi data, display data, dan penarikan kesimpulan).

\section{Pembahasan}

Pada bagian ini dikemukakan bahasan hasil penelitian tentang human capital mahasiswa Universitas Terbuka sebagai guru honorer di SD Negeri 01 Pangkalan, SD Negeri 10 Pangkalan dan SD MIS Pangkalan, Kecamatan Pangkalan Koto Baru, Kabupaten Lima Puluh Kota. Peneliti melihan human capital mahasiswa Universitas Terbuka sebagai guru honorer dari kesehariannya selama di sekolah dan menjalankan perannya sebagai guru. Tidak hanya dilihat dari rutinitasnya mengajar di sekolah, tapi dilihat dari semua kegiatan yang dilakukan oleh guru honorer yang berstatus mahasiswa di lingkungan sekolah. Adapun aspek 
modal yang peneliti amati meliputi; 1) pendidikan, 2) pengetahuan, 3) gagasan (ide), 4) kesehatan, 6) kreativitas, 7) keterampilan, dan 8) produktivitas kerja

Modal diri yang dimiliki oleh mahasiswa Universitas Terbuka sebagai guru honorer di SD Negeri 01 Pangkalan, SD Negeri 10 Pangkalan dan MIS Pangkalan, Kecamatan Pangkalan Koto Baru, Kabupaten Lima Puluh Kota dianalisis dengan human capital theory Theodore W.Schultz. Human capital theory didasarkan pada asumsi bahwa pendidikan formal sangat terkait dan dibutuhkan untuk meningkatkan kapasitas produksi organisasi. ${ }^{10}$ Theodore mengungkapkan konsep modal manusia (Human Capital) ini pada intinya menganggap bahwa manusia merupakan suatu bentuk modal atau kapital sebagaimana bentuk-bentuk kapital lainnya, seperti mesin, teknologi, tanah, uang dan material. Manusia yang memiliki modal ketika melakukan peran dengan sungguh-sungguh akan mendapatkan hasil yang luar biasa. Jika dilihat dari teori human capital, mahasiswa Universitas Terbuka ini, memiliki modal diri dilihat dari beberapa aspek. Modal diri yang dimiliki oleh mahasiswa Universitas Terbuka ini merupakan modal untuk menjalankan perannya sebagai seorang pendidik. Berikut adalah human capital mahasiswa Universitas Terbuka sebagai guru honorer di SD 01 Pangkalan, SD 10 Pangkalan dan MIS Pangkalan adalah:

\section{Rajin Bertanya Dengan Guru Tetap}

Guru honorer rajin bertanya dengan guru tetap. Begitupun dengan pengetahuan guru honorer tentang perencanaan pembelajaran didapatkan dari hasil bertanya dengan guru tetap tempat mereka mengajar. Jika hal ini dianalisis dengan teori human capital maka modal diri yang diperoleh oleh guru honorer yang berstatus mahasiswa ini termasuk ke dalam aspek pengetahuan. Pengetahuan seseorang dengan orang lain berbeda-beda. Pengetahuan merupakan hasil dari penginderaan terhadap objek tertentu. Dimana didapatkan oleh seseorang dari indra penglihatan, pendengaran, penciuman, rasa dan raba. Dengan pengetahuan yang didapatkan guru honor ketika sering bertanya kepada guru tetap tentang cara membuat perencanaan pembelajaran, maka guru honorer ini memahami cara memuat perencanaan pembelajaran.

\section{Memiliki Sifat Yang Pantang Menyerah}

Seorang guru honorer yang berstatus sebagai mahasiswa sedang mengikuti guru yang lain untuk mengajar di kelas. Guru honorer tersebut memperhatikan guru mengajar dari awal sampai akhir pembelajaran.Produktifitas guru honorer dalam melaksanakan pembelajaran. Menurut Sinungan, produktifitas kerja adalah suatu pendekatan interdisipliner untuk menentukan tujuan yang efektif, pembuatan rencana, aplikasi penggunaan cara yan menjaga adanya kualitas yang tinggi. ${ }^{11}$ Tidak menyerah dan selalu belajar untuk menjadi guru yang baik dan pantas melaksanakan pembelajaran merupakan produktifitas kerja seorang guru honorer. Selalu bertanya dengan guru tetap tentang kekurangan dalam mengajar. Menerima saran yang

\footnotetext{
${ }^{10}$ Nuzulul Kusuma Putri. Peran Human Capital terhadap Kesuksesan Organisasi: Karyawan Adalah Investasi. file:///F:/download-fullpapers-akk60199870a9full.pdf, diunduh tanggal 7 Januari 2019.

${ }^{11}$ Nasron dan Tri Bodro Astuti.Faktor-Faktor Yang Mempengaruhi Produktifitas Kerja (Studi Pada Karyawan Bagian Produksi PT Mazuvo Indo). Sekolah Tinggi Ilmu Ekonomi Widya Manggala. Semarang. https://media .neliti.com, Diunduh pada tanggal 26 Maret 2019
} 
diberikan oleh guru tetap. Memperbaiki kesalahan dan membuktikan bahwa dia mampu menjadi guru yang baik. Hal ini membuktikan bahwa guru ini benar-benar menjalankankan perannya sebagai guru honorer. Selalu bertanya dengan guru tetap tentang kekurangan dalam mengajar. Menerima saran yang diberikan oleh guru tetap. Memperbaiki kesalahan dan membuktikan bahwa dia mampu menjadi guru yang baik. Jika dianalisis menggunakan teori human capital, semangat pantang menyerah guru honorer untuk mempelajari cara melaksanakan pembelajaran di kelas adalah cara menunjukkan kualitas diri dan termasuk kedalam produktifitas kerja.

\section{Memiliki Ide-Ide Dalam Mengelola Kelas}

Kreativitas guru honorer dalam mengelola kelas. Untuk membuat proses pembelajaran menjadi lebih bervariasi dan menumbuhkan semangat belajar anak-anak, guru pembantu membuat proses pembelajaran yang menyenangkan. Pembelajaran tidak hanya fokus pada materi tapi juga diselingi dengan permainan. Jika dianalisis dengan teori human capital yang dilakukan oleh guru honorer ini adalah sebuah pemikiran yang menhasilkan sesuatu yang bermanfaat yang termasuk kedalam Kreativitas. Kreativitas guru honorer untuk menciptakan permainan dan memberi reward membuat proses pembelajaran lebih menyenangkan. Menurut teori Human Capital salah satu modal yang dimiliki oleh individu adalah kreativitas. Kreativitas adalah kemampuan dalam berpikir dalam meraih hasil hasil yang variatif, baru yang memungkinkan untuk diterapkan dalam berbagai bidang baik itu keilmuan, olahraga, kesusasteraan dan juga bidang kehidupan lainnya. Kreativitas dalam dunia pendidikan dapat dengan menciptakan hal-hal baru yang menunjang berjalannya pendidikan. Guru honorer yang berstatus mahasiswa mempunyai kreativitas untuk membuat pembelajaran lebih menyenangkan. Hal ini memberikan dampak positi kepada peserta didik. Peserta didih lebih menyukai belajar karena tidak membosankan.

\section{Memiliki Pengalaman Dalam Kegiatan Ekstrakurikuler dan Mudah Dekat Dengan Peserta Didik.}

Kegiatan ekstrakurikuler merupakan kegiatan yang dilaksanakan di sekolah diluar kegiatan proses belajar mengajar. Bagi guru honorer yang berstatus sebagai mahasiswa, kegiatan ekstrakurikuler merupakan kesempatan bagus untuk mendekatkan diri dengan peserta didik. Guru honorer akan lebih mengenal peserta didik dengan adanya kegiatan ini. Begitupun sebaliknya, ketika peserta didik canggung belajar dengan guru honorer, maka kegiatan ekstrakurikuler akan menjadi ajang untuk mengenal gurunya. Keterampilan dimiliki oleh seseorang dari pengalaman yang di lalui. Guru honorer memiliki keterampilan dalam bidang ekstrakurikuler. Hal ini menjadikan dirinya mampu bersosialisasi di bidang ini. Berdasarkan teori human capital, seseorang yang melakukan sesuatu dengan sepenuh hati akan menghasilkan sesuatu yang luar biasa. salah satu aspek modal diri yang dimiliki oleh seseorang adalah keterampilan. Apabila seseorang memiliki keterampilan dalam bidang tertentu dan melaksanakannya dengan sepenuh hati, maka akan menghasilkan hasil yang memuaskan. 
Menjadi seorang guru tidak hanya memberikan pembelajaran kepada peserta didik, tapi juga harus bisa mendekatkan diri dengan peserta didik. ${ }^{12}$ Sebagai guru honorer, mahasiswa Universitas Terbuka beranggapan bahwa bisa dekat dengan peserta didik adalah nilai lebih bagi seorang guru sehingga ilmu yang diberikan mudah diterima oleh peserta didik. Gagasan dan ide guru honorer dalam membuat kegiatan di sekolah. Guru honorer memiliki keterampilan sehingga dapat disalurkan dalam kegiatan ekstrakurikuler. Hal ini menjadikan dirinya mampu bersosialisasi dalam bidang ekstrakurikuler. Sehingga dapat mendekatkan diri dengan peserta didik. Jika dianalisis menggunakan teori human capital, seseorang yang melakukan sesuatu dengan sepenuh hati akan menghasilkan sesuatu yang luar biasa. salah satu aspek modal diri yang dimiliki oleh seseorang adalah keterampilan. Apabila seseorang memiliki keterampilan dalam bidang tertentu dan melaksanakannya dengan sepenuh hati, maka akan menghasilkan hasil yang memuaskan.

\section{Memiliki Ide Dalam Membuat Kegiatan di Sekolah.}

Dalam menjalankan perannya sebagai guru honorer, mahasiswa Universitas Terbuka melakukan pendekatan dengan individu-individu di lingkungan sekolahnya. Hal ini dilakukan agar tidak canggung menjalankan perannya sebagai seorang pendidik. Keterampilan guru honorer dalam kegiatan ekstrakurikuler. Guru honorer memiliki pandangan untuk kemajuan sekolah ke depannya. Hal ini juga dapat membuat guru honorer menjadi dekat dengan guruguru lain. Pandangan ini terlihat dari guru honorer SD 01 Pangkalan untuk membuat sekolah layak dijadikan sebagai pelaksana ujian Pra UN, maka lingkungan sekolah harus bersih dan indah terutama lokal yang akan dipakai. Sedangkan pandangan guru honorer SD MIS Pangkalan, untuk membuat sekolah dikenal oleh orang banyak maka harus dibuat sesuatu yang berbeda seperti dengan membuat kegiatan mengaji setelah jam pelajaran selesai. Jika dianalisis pemikiran menggunakan guru honorer ini dengan teori human capital maka pemikiran guru honor ini merupakan ide atau gagasan. Ide atau gagasan adalah salah satu aspek modal diri yang dimiliki oleh seorang individu. Guru honorer yang berstatus sebagai mahasiswa Universitas Terbuka memiliki ide atau gagasan yang merupakan modal diri yang dimilikinya dalam menjalankan perannya sebagai seorang guru.

Teori Human Capital dikemukakan oleh Theodore W.Schult yang mengargumentasikan bahwa pendidikan formal sangat terkait dan dibutuhkan untuk meningkatkan kapasitas produksi organisasi. Theodore mengungkapkan konsep modal manusia (Human Capital) ini pada intinya menganggap bahwa manusia merupakan suatu bentuk modal atau kapital sebagaimana bentuk-bentuk kapital lainnya, seperti mesin, teknologi, tanah, uang dan material. Manusia yang memiliki modal ketika melakukan peran dengan sungguh-sungguh akan mendapatkan hasil yang luar biasa. Setiap individu memiliki modal di dalam dirinya sehingga mampu untuk menjalankan aktivitasnya. Individu yang melakukan sesuatu hal dengan sungguh-sungguh maka akan menghasilkan sesuatu yang luar biasa.

\footnotetext{
${ }^{12}$ Fernandes, R. (2018). ADAPTASI SEKOLAH TERHADAP KEBIJAKAN PENDIDIKAN INKLUSIF. SOCIUS, 4(2), 119-125.
} 


\section{Kesimpulan}

Berdasarkan hasil penelitian penulis tentang human capital mahasiswa Universitas Terbuka sebagai guru honorer, dapat diambil keismpulannya sebagai berikut:

1. Guru honorer yang berstatus sebagai mahasiswa Universitas Terbuka di SD 01 Pangkalan, SD 10 Pangkalan dan MIS Pangkalan, Kecamatan Pangkalan Koto Baru , Kabupaten Lima Puluh Kota memiliki modal diri sehingga mampu menjalankan perannya sebagai guru. Adapun human capital guru honorer ini adalah sebagai berikut: rajin bertanya dengan guru tetap, memiliki sifat yang pantang menyerah, memiliki ideide dalam mengelola kelas, memiliki pengalaman dalam kegiatan ekstrakurikuler, mudah dekat dengan peserta didik dan memiliki ide dalam membuat kegiatan di sekolah.

2. Jika dilihat dari teroi human capital, modal diri yang dimiliki oleh guru honorer terlihat dari:

a. Aspek pengetahuan dimiliki oleh guru honorer karena sering bertanya kepada guru tetap dalam memenuhi tugas-tugasnya sebagai guru, sehingga karena keseriusannya ia memiliki pengetahuan dan menyelesaikan tugasnya.

b. Aspek produktifitas kerja dimiliki oleh guru honorer karena sikap pantang menyerah dalam belajar menjadi guru yang professional dengan mengajar peserta didiknya di dalam kelas.

c. Aspek kreativitas dimiliki oleh guru honorer karena ide-ide yang disalurkannya dalam mengelola kelas, sehingga kelas berjalan kondusif dan peserta didik lebih antusias dalam belajar.

d. Aspek keterampilan dimiliki oleh guru honorer karena memiliki pengalaman dalam kegiatan ekstrakurikuler sehingga mampu memberikan ilmunya. Hal ini membuat guru honorer mudah dekat dengan peserta didik.

e. Aspek ide/gagasan dimiliki oleh guru honorer dalam memberikan pendapat demi memajukan sekeolah menjadi nilai tambahnya sebagai seorang guru.

\section{Daftar Pustaka}

Alfa Farah \& Erlinda Puspita Sari. (2014). Modal Manusia dan Produktivitas. Universitas Diponegoro. www.07_SARI.pdf (diakses tanggal 7 Januari 2019)

Almufdi. (2018). "Strategi Mahasiswa Universitas Terbuka dalam Proses Perkuliahan; Studi Kasus Mahasiswa UT di Pokjar Rao Kabupaten Pasaman". http://www.sosiologi.fis.unp.ac.id. Diunduh pada tanggal 2 Desember 2018

Data Pokok Pendidikan Dasar dan Menengah, Direktorat Jenderal Pendidikan Dasar dan Menengah, Kementerian Pendidikan dan Kebudayaan (diakses 28 Oktober 2018)

Emzir. (2010). Metode Penelitian Kualitatif Analisis Data. Jakarta: PT Raja Grafindo Persada Faatihatul Ghaybiyyah.(2017). Dinamika Psyichological Well-Being (Kesejahteraan Psikologis) Guru Honorer SDN 11 Tiudan, Kecamatan Gondang, Kabupaten Tulungangung. Universitas Islam Negeri Maulana Malik Ibrahim. Malang.. www.utheses.uin-malang.ac.id (diakses tanggal 27 Mei 2017)

Fernandes, R. (2018). Adaptasi Sekolah Terhadap Kebijakan Pendidikan Inklusif. Socius, 4(2), $119-125$.

Hasbullah. (2012). Dasar-Dasar Ilmu Pendidikan. Jakarta: Rajawai Pers 
Iwan Sukoco \& Dea Prameswari. (2017). Pendekatan Human Capital Untuk Mengelola Sumber Daya Manusia Yang Lebih Produktif. Universita Padjajaran. Jurnal AdBispreneur Vol. 2, No. 1, April 2017. www.12921-27827-1-PB.pdf (diakses tanggal 7 Januari 2018)

Lawang, Robert M.Z. (2004). Kapital Sosial Dalam Perspektif Sosiologik Suatu Pengantar.Depok.FISIP UI Fakultas Ilmu Sosial dan Politik Universitas Indonesia.

Marten Masoka, dkk. (2017). "Studi Eksplorasi Kualifikasi dan Kompetensi Guru Bidang Studi Biologi SMP-SMA Sebagai Basis Program Peningkatan Pendidikan”. Jurnal Pendidikan: Teori, Penelitian, dan Pengembangan. Volume: 2 Nomor 4 Bulan April Tahun 2017. Halaman 516-523 http://www.media.neliti.com (diakses tanggal 28 Oktober 2018)

Nanang Martono. (2012). Metode Penelitian Kualitatif. Jakarta: Rajawali Pers

Nuzulul Kusuma Putri. (2019). "Peran Human Capital terhadap Kesuksesan Organisasi:

Karyawan Adalah Investasi". Universitas Airlangga. file:///F:/download-fullpapersakk60199870a9full.pdf (diakses tanggal 7 Januari 2019)

Peraturan Pemerintah Republik Indonesia Nomor 19 Tahun 2017 Tentang Perubahan Atas Peraturan Pemerintah Nomor 74 Tahun 2008 Tentang Guru. http://www.hukumonline.com (diakses tanggal 16 Desember 2018)

Sindikker.dikti.go.id/dok/uu/uu no 142005 (diakses pada hari Minggu, tanggal 7 Mei 2017)

Sitoresmi Arening Tivas.2015. Kreativitas Guru dalam Peningkatan Hasil Belajar Siswa Pada Pembelajaran Tematik Kelas 1 di Madrasah Ibtidaiyah Negeri Kauman Utara Jombang. http://www.etheses.uin-malang.ac.id. Diunduh pada tanggal 2 Desember 2018

Undang-Undang Republik Indonesia Nomor 20 Tahun 2003 Tentang Sistem Pendidikan Nasional. http://www.kelembagaan.risetdikti.go.id (diakses tanggal 28 Oktober 2018)

Yuliani, R., Junaidi, J., \& Fernandes, R. (2018). Faktor Pendorong Anak Nelayan Melanjutkan Pendidikan Ke Jenjang Slta (Studi Kasus: Desa Naras I Kecamatan Pariaman Utara Kota Pariaman). Jurnal Perspektif, 1(4), 44-50. 